\title{
Two defects contribute to hypothalamic leptin resistance in mice with diet-induced obesity
}

\author{
Karim El-Haschimi, Dominique D. Pierroz, Stanley M. Hileman, \\ Christian Bjørbæk, and Jeffrey S. Flier
} Department of Medicine, Division of Endocrinology, Beth Israel Deaconess Medical Center, Harvard Medical School,
Boston, Massachusetts, USA

Address correspondence to: Jeffrey S. Flier, Department of Medicine, Division of Endocrinology, Beth Israel Deaconess Medical Center, 99 Brookline Avenue, Boston, Massachusetts 02215, USA. Phone: (617) 667-2151; Fax: (617) 667-2927; E-mail: jflier@caregroup.harvard.edu.

Karim El-Haschimi and Dominique D. Pierroz contributed equally to this work.

Received for publication March 13, 2000, and accepted in revised form May 9, 2000.

\begin{abstract}
Obesity in humans and in rodents is usually associated with high circulating leptin levels and leptin resistance. To examine the molecular basis for leptin resistance, we determined the ability of leptin to induce hypothalamic STAT3 (signal transducer and activator of transcription) signaling in C57BL/6J mice fed either low-fat or high-fat diets. In mice fed the low-fat diet, leptin activated STAT3 signaling when administered via the intraperitoneal (ip) or the intracerebroventricular (icv) route, with the halfmaximal dose being 30-fold less when given by the icv route. The high-fat diet increased body-weight gain and plasma leptin levels. After 4 weeks on the diet, hypothalamic STAT3 signaling after ip leptin administration was equivalent in both diet groups. In contrast, peripherally administered leptin was completely unable to activate hypothalamic STAT3 signaling, as measured by gel shift assay after 15 weeks of high-fat diet. Despite the absence of detectable signaling after peripheral leptin at 15 weeks, the mice fed the high-fat diet retained the capacity to respond to icv leptin, although the magnitude of STAT3 activation was substantially reduced. These results suggest that leptin resistance induced by a high-fat diet evolves during the course of the diet and has at least two independent causes: an apparent defect in access to sites of action in the hypothalamus that markedly limits the ability of peripheral leptin to activate hypothalamic STAT signaling, and an intracellular signaling defect in leptinresponsive hypothalamic neurons that lies upstream of STAT3 activation.
\end{abstract}

J. Clin. Invest. 105:1827-1832 (2000).

\section{Introduction}

Leptin, the protein product of the $o b$ gene, is predominantly secreted from white adipose tissue, and acts on the brain to regulate food intake, energy expenditure, and neuroendocrine function (1-4). In genetically obese $(o b / o b)$ mice that lack functional leptin, recombinant leptin is highly effective at reversing obesity $(2,3,5)$. However, most cases of obesity in rodents (6) and humans (7) are associated with high circulating leptin levels; the resistance to leptin that characterizes these states has not yet been explained. Potential sites for leptin resistance include the blood-brain-barrier transport system $(8,9)$ and the leptin signaling mechanism in leptin-responsive neurons in the hypothalamus (10). Rodents with obesity induced by high-fat diet (dietinduced obesity, or DIO) become hyperleptinemic, and food intake and body weight are resistant to the effects of exogenous leptin administered peripherally, such as by an intraperitoneal (ip) route $(11,12)$. Such rodents do respond to leptin given by the intracerebrovascular (icv) route, consistent with a defect in the blood-brain barrier $(11,12)$. Upon peripheral administration of leptin to normal mice, leptin rapidly induces hypothalamic signaling through the STAT3 pathway, as evidenced by induction of a gel mobility shift using a STAT3 DNA element and hypothalamic nuclear extracts (10). The status of leptin signaling has not heretofore been assessed in mice during the course of development of DIO. We therefore examined hypothalamic STAT3 signaling induced by ip or icv leptin in mice fed diets containing $10 \%$ or $45 \%$ fat for either 4 or 15 weeks.

\section{Methods}

Animals and diets. Male C57BL/6J mice (3 weeks old) were purchased from The Jackson Laboratory (Bar Harbor, Maine, USA). The animals and procedures used were in accordance with the guidelines and approval of the Institutional Animal Care and Use Committees of the Harvard Medical School and Beth Israel Deaconess Medical Center. Upon arrival, mice were fed a standard rodent chow for 1 week to acclimate, and were housed in groups of nine. Room temperature was maintained between $21-23^{\circ} \mathrm{C}$, and a 12 -hour light, 12 -hour dark cycle was used. When mice were 4 weeks of age, they were divided into two groups. One group was given a high-fat diet containing 45\% fat (D12451; Research Diets Inc., New Brunswick, New Jersey, USA), and the other group was given a low-fat diet (D12450; Research 
Diets Inc.) containing $10 \%$ fat. Body weight and food intake were measured weekly at the same time of day. Groups of mice were removed from these cohorts at specific timepoints. After central and peripheral injections, mice were deeply anesthetized by inhalation of Metofane (Mallinckrodt Veterinary Inc., Mundelein, Illinois, USA) and then decapitated. Hypothalami were quickly dissected and either used for electrophoretic mobility shift assay (EMSA) or frozen and used for RT-PCR.

Hormone and hormone assays. Recombinant mouse leptin (Eli Lilly and Co., Indianapolis, Indiana, USA) was dissolved in sterile PBS ( $\mathrm{pH}$ 7.4) containing 0.1\% BSA before ip or icv injections. Plasma leptin levels were determined by radioimmunoassay (Linco Research Inc., St. Charles, Missouri, USA).

Leptin icv injection. After mice were anesthetized with Metofane, the skull was exposed and the bregma was located. The right lateral ventricle (coordinates: $0.5 \mathrm{~mm}$ caudal and $1 \mathrm{~mm}$ lateral from bregma, depth $2.5 \mathrm{~mm}$ ) was injected with $0.5 \mu \mathrm{g}$ of leptin or buffer in a volume of $3 \mu \mathrm{L}$ with an Exmire Microsyringe (Ito Corp., Fuji, Japan).

Microvessel isolation. Microvessel isolation was performed as described earlier (13). Briefly, microvessels were isolated from each brain after removal of the cerebellum and brain stem. The forebrains were dissected, stripped of the pia-arachnoid, and homogenized in a solution containing $118 \mathrm{mM} \mathrm{NaCl}, 5.4 \mathrm{mM} \mathrm{KCl}, 1.8$ $\mathrm{mM} \mathrm{CaCl}_{2}, 1.0 \mathrm{mM} \mathrm{MgSO}_{4}, 1.0 \mathrm{mM} \mathrm{NaH}_{2} \mathrm{PO}_{4}, 5.5 \mathrm{mM}$ D-glucose, $0.2 \%(\mathrm{wt} / \mathrm{vol}$ ) fraction $\mathrm{V}$ albumin, and 28 $\mathrm{mM}$ HEPES ( $\mathrm{pH}$ 7.4). The homogenates were filtered through nylon meshes $(147 \mu \mathrm{m}, 74 \mu \mathrm{m}$, and $37 \mu \mathrm{m})$. The microvessels were gently removed from the $74-\mu \mathrm{m}$ and $37-\mu \mathrm{m}$ meshes, washed with PBS three times, and centrifuged at $200 \mathrm{~g}$ for 20 minutes.

Quantitative RT-PCR. The following primers were used for specific PCR amplification. SOCS-3 (suppressor of cytokine signaling): 5'-ACCAGCGCCACTTCTTCACG-3' and 5'-GTGGAGCATCATACTGATCC-3'; PIAS-3 (a protein inhibitor of activated STAT): 5'-AGGAGAAACTGACTGCTGACC- $3^{\prime}$ and 5'-AATCAGCGACTCATAGGGAGCC-3';

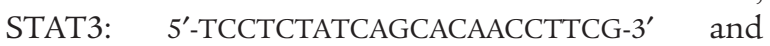
5'-AGCTGCTGCATCTTCTGTCTGG-3'; ObRa (short isoform of the leptin receptor): $5^{\prime}$-ACACTGTTAATTTCACACCAGAG-3' and 5'-AGTCATTCAAACCATTAGTTTAGG3'; ObRall forms (designed to detect all known forms of ObR): 5'-ACAGCGTGCTTCCTGGGTCTTC-3' and 5'CACAGTGCTTCCCACTAGTGATTGG-3'; ObRb (long form of the leptin receptor): $5^{\prime}$-GGGTAATACTTAAACAGTGACC$3^{\prime}$ and $5^{\prime}$-CTATCTGAAAATAAAAACTTCATG-3'; $\beta$-actin: $5^{\prime}$ CGTACCACGGGCATTGTGATGG- $3^{\prime}$ and $5^{\prime}$-TTTGATGTCACGCACGATTTCCC-3'. Quantitative RT-PCR was performed as described earlier (14) with the following modifications. After initial denaturation at $96^{\circ} \mathrm{C}$ for 3 minutes, the samples were subjected to cycles of amplification: denaturation at $95^{\circ} \mathrm{C}$ for 1 minute, annealing at $55^{\circ} \mathrm{C}$ for 1 minute, and elongation at $72^{\circ} \mathrm{C}$ for $45 \mathrm{sec}-$ onds. Preliminary PCR experiments showed that the rate of amplification was linear for a limited number of cycles, so the samples were subjected to 17 cycles of amplification for $\beta$-actin, 23 cycles for PIAS- 3 and STAT3, 25 cycles for SOCS-3 and ObRb, and 29 cycles for ObRa and ObRall. Ten microliters of the reaction mixture were combined with $5 \mu \mathrm{L}$ of sequencing stop solution and heated at $85^{\circ} \mathrm{C}$ for 3 minutes; $4 \mu \mathrm{L}$ was loaded on to $4 \%$ urea-acrylamide gels. Results for ObRa and ObRall forms were normalized to $\beta$-actin.

Nuclear extraction and EMSA. Nuclear extractions were done as described earlier (15). Briefly, animals were deprived of food overnight. Thirty minutes after icv or ip administration of leptin or buffer, the animals were anesthetized and then decapitated. The hypothalami were dissected and homogenized in 100:1 (vol/vol) buffer A (10 $\mathrm{mM} \mathrm{KCl}, 1.5 \mathrm{mM} \mathrm{MgCl}_{2}, 10 \mathrm{mM}$ HEPES at $\mathrm{pH} 7.9,1 \mathrm{mM}$ DTT, $1 \mathrm{mM} \mathrm{Na}_{3} \mathrm{VO}_{4}$, and $1 \times$ complete TM protease inhibitor from Boehringer Mannheim Biochemicals Inc., Indianapolis, Indiana, USA). The samples were centrifuged at 2,000 $\mathrm{g}$ for 10 minutes at $4^{\circ} \mathrm{C}$. The pellets were resuspended in a 4:1 ratio of buffer $A$ and centrifuged at $2,000 \mathrm{~g}$ for 10 minutes at $4^{\circ} \mathrm{C}$. The pellets were resuspended in 2 volumes of buffer $\mathrm{B}(420 \mathrm{mM} \mathrm{NaCl}, 10 \mathrm{mM}$ KCl, 20 mM HEPES at pH 7.9, 20\% glycerol, 1 mM DTT, $1 \mathrm{mM} \mathrm{Na}_{3} \mathrm{VO}_{4}$, and $1 \times$ complete TM protease inhibitor), and were extracted by vigorous rocking at $4^{\circ} \mathrm{C}$ for $30 \mathrm{~min}$ utes. The nuclear extracts were finally clarified by centrifugation at $14,000 \mathrm{~g}$ for 20 minutes at $4^{\circ} \mathrm{C}$. The supernatant was diluted tenfold in buffer C $(10 \mathrm{mM} \mathrm{KCl}, 20$ mM HEPES at pH 7.9, 20\% glycerol, 1 mM DTT, $1 \mathrm{mM}$ $\mathrm{Na}_{3} \mathrm{VO}_{4}$, and $1 \times$ complete TM protease inhibitor) and centrifuged at $16,000 \mathrm{~g}$ for 10 minutes at $4^{\circ} \mathrm{C}$. The supernatant was concentrated on Microcon-50 ultrafiltration columns (Millipore Corp., Bedford, Massachusetts, USA), and the filtrate was stored at $-80^{\circ} \mathrm{C}$ until use in the EMSA.

EMSA was performed as previously described (10, 16). The entire nuclear extract from each hypothalamus was added to binding buffer $\mathrm{E}(40 \mathrm{mM} \mathrm{KCl}, 1 \mathrm{mM}$ $\mathrm{MgCl}_{2}, 20 \mathrm{mM}$ HEPES at $\mathrm{pH} 7.9,4 \%$ Ficoll (Pharmacia, Peapack, New Jersey, USA), $0.5 \mathrm{mM}$ DTT, and $100 \mu \mathrm{g}$ EGTA) containing $3 \mu \mathrm{g}$ dI-dC (Pharmacia) that included 100,000 cpm of the ${ }^{32}$ P-labeled double-stranded oligonucleotide probe. The final volume was $60 \mu \mathrm{L}$. The mixture was incubated for 20 minutes at room temperature, and was resolved by $5 \%$ native PAGE in $0.5 \times \mathrm{TBE}$ at $4^{\circ} \mathrm{C}$. The probe was generated by first annealing two oligonucleotides: $5^{\prime}$-CGCTCCATTTCCCGTAAATCAT-3' and 5'-CGCTCATGATTTACGGGAAATG3' (STAT-inducible element mutant 67) (17). This step was followed by a fill-in reaction of the five base overhangs using T7 polymerase (GIBCO BRL, Gaithersburg, Maryland, USA) and $\left[{ }^{32} \mathrm{P}\right] \alpha$-deoxynucleotide triphosphates (each $222 \mathrm{TBq} / \mathrm{mmol}, 740 \mathrm{MBq} / \mathrm{mL}$; NEN Life Science Products, Boston, Massachusetts, USA). Unincorporated nucleotides were removed using a G25 Quick Spin column (Boehringer Mannheim Biochemicals Inc.). After drying, gels were placed in a PhosphorImager cassette (Molecular Dynamics Inc., Sunnyvale, California, USA) for 12-16 hours.

Statistical analysis. Individual variations were analyzed by Fisher analysis or Student's $t$ test. 


\section{Results and Discussion}

The aim of this study was to examine the basis for the leptin resistance that develops when $\mathrm{C} 57 \mathrm{BL} / 6 \mathrm{~J}$ mice are placed on a high-fat diet. Mice were studied after 4 weeks and 15 weeks of low-fat or high-fat diet. Leptin was administered by either the ip or icv route, after which leptin signaling to activate STAT3 in the hypothalamus was assessed. To better understand the characteristics of leptin signaling to STAT3 in the hypothalamus, we first performed a dose-response study for STAT3 activation by gel shift assay after ip vs. icv leptin in mice fed a normal chow diet (Figure 1a). STAT3 activation was dose dependent with both routes of administration. The dose-response curve for icv leptin was shifted 30-fold to the left. The half-maximal dose of leptin was $0.5 \mu \mathrm{g}$ after icv administration, and approximately $15 \mu \mathrm{g}$ after ip administration. A dose of $30 \mu \mathrm{g}$ icv leptin was no more effective than $5 \mu \mathrm{g}$ icv (data not shown). The maximal response was obtained $15-30$ minutes after $0.5 \mu \mathrm{g}$ icv leptin (Figure 1b). This is similar to the maximalresponse timepoint observed after intravascular injection that was reported by Vaisse et al. (10).

Mice fed the high-fat diet had a measurable, significant weight increase after 4 days; after 15 weeks they weighed $24 \%$ more than those fed the low-fat diet (Figure 2a). Mice fed the high-fat diet also ingested more calories per day (Figure 2b). As expected, high-fat feeding and attendant obesity were associated with increased leptin levels (Figure 2c). The ability of leptin to induce STAT3 signaling was first studied after 4 weeks on the diets. After an overnight fast, mice were administered $100 \mu \mathrm{g}$ recombinant mouse leptin by the ip route. Thirty minutes later, hypothalami were isolated, nuclear extracts were obtained, and STAT3 activation was assessed by EMSA. After 4 weeks on the diets, peripheral leptin treatment induced STAT3 DNA binding activity to an equivalent extent in hypothalami of mice fed low- and high-fat diets (Figure 3, a and b). In contrast, after 15 weeks on the diets, the same dose of ip leptin that was effective in mice fed the low-fat diet was unable to induce detectable STAT3 DNA binding activity in hypothalami of mice fed the high-fat diet (Figure 3, c and d). We obtained the same result in another independent experiment with six mice in each group (data not shown). Thus, prolonged highfat feeding induced profound resistance to peripherally administered leptin as measured by STAT3 signaling in the hypothalamus. It is worth noting that even after 4 weeks on a high-fat diet, mice appear to be in positive energy balance, as suggested by early weight gain (Figure 2 ), and they may therefore already have some degree of leptin resistance. We did not directly assess leptin resistance by evaluating the effects of leptin administration on food intake and body weight at 4 weeks in the current study. If leptin resistance exists at this point, our data suggest that the mechanism is different, or it is of much smaller magnitude than that seen after 15 weeks.

If the absence of leptin signaling after 15 weeks of high-fat diet was due to a defect in access of peripheral leptin to sites of action in the hypothalamus, then icv leptin administration should be able to overcome this defect. Consistent with this hypothesis, icv leptin given at a much lower dose than was given intraperitoneally $(0.5 \mu \mathrm{g}$ vs. $100 \mu \mathrm{g})$ clearly induced STAT3 activation in mice with 15 weeks of DIO (Figure 3e). Thus, one component of the leptin resistance in mice with 15 weeks of DIO can be attributed to a failure to deliver leptin to its sites of action in the hypothalamus, presumably by a defect in the blood-brain-barrier transport system. Importantly, however, whereas icv leptin can induce signaling in mice with DIO, the extent of this induction is $75 \%$ lower than that in mice fed the low-fat diet (Figure 3f). This finding was confirmed in an independent experiment with five mice in each group (data not shown). The results demonstrate that in addition to an apparent defect in leptin access to the hypothalamus, a signaling defect also exists upstream of STAT3 activation in leptin-responsive hypothalamic neurons
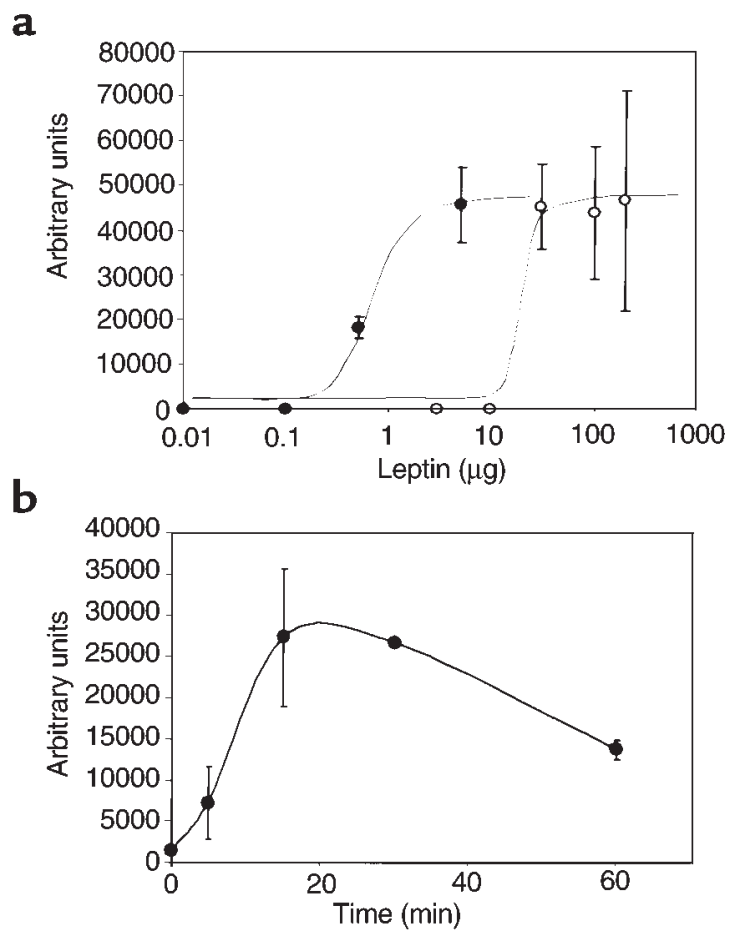

Figure 1

Gel shift assays of dose response for STAT3 activation after ip (open circles) and icv (filled circles) leptin administration, and time course of STAT3 activation after icv leptin administration in 8-week-old C57BL/6J mice on a standard chow diet. Each dose and timepoint represents four animals. (a) Dose response for STAT3 activation in hypothalami of ip- and icv-injected mice. For the icv injections, doses of leptin were $0 \mu \mathrm{g}, 0.01 \mu \mathrm{g}, 0.1 \mu \mathrm{g}, 0.5$ $\mu \mathrm{g}$, and $5 \mu \mathrm{g}$ in $3 \mu \mathrm{L}$ phosphate-buffered saline. For the ip injections, doses of leptin were $0 \mu \mathrm{g}, 0.1 \mu \mathrm{g}, 5 \mu \mathrm{g}, 10 \mu \mathrm{g}, 50 \mu \mathrm{g}, 100$ $\mu \mathrm{g}$, and $200 \mu \mathrm{g}$ in $100 \mu \mathrm{L}$ phosphate-buffered saline. Mice were sacrificed 30 minutes after injection. Data are presented as mean \pm SEM. (b) Time course of STAT3 activation by leptin in hypothalami of icv-injected mice. Leptin $(0.5 \mu \mathrm{g})$ was injected and animals were sacrificed $0,5,15,30$, and 60 minutes later. The gels were quantified by Phosphorlmager ${ }^{\circledR}$ analysis. Data are presented as mean \pm SEM. 
in these DIO mice. To verify that the STAT3 DNA binding activity in the hypothalamus after leptin administration was dependent on the long form of the leptin receptor, we examined STAT3 DNA binding activity after administration of $100 \mu \mathrm{g}$ ip leptin to $d b / d b$ mice, which lack the long form of leptin receptor $(18,19)$. As expected, we found no leptin-induced STAT3 DNA binding activity in hypothalami of $d b / d b$ mice, whereas controls showed a strong signal (data not shown).

These results suggest that at least two defects underlie the leptin resistance that develops during the course
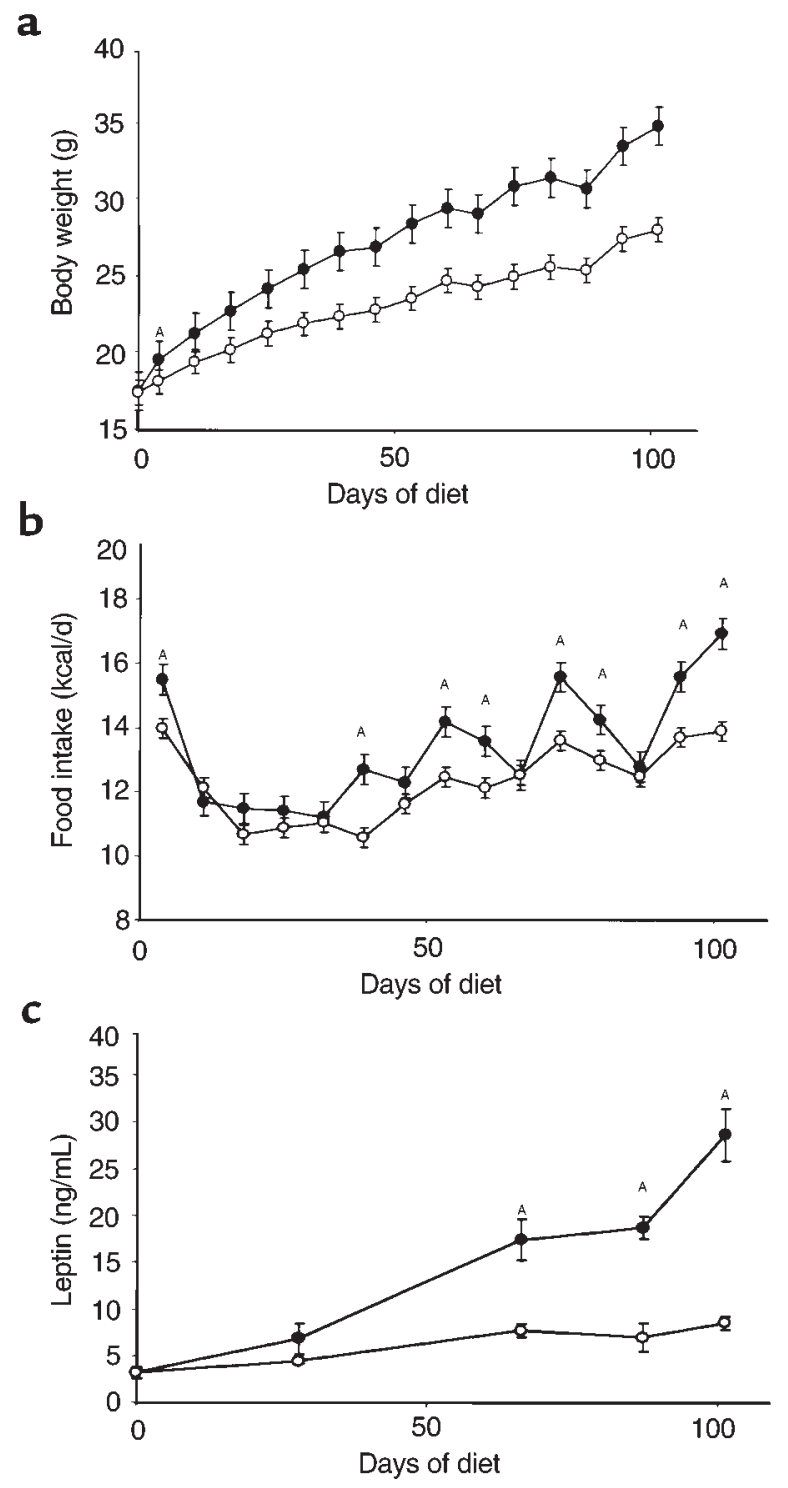

\section{Figure 2}

Physiological characteristics of male C57BL/6J mice fed high-fat $(n=22)$ and low-fat $(n=22)$ diets. Dietary treatment began when mice were 4 weeks old and lasted for 15 weeks. Filled circles represent a diet of $45 \%$ fat; open circles represent a diet of $10 \%$ fat. Data are presented as mean \pm SEM. (a) Effects of diets on body weight. ${ }^{A}$ First day of significant weight difference $(P<0.001)$ between mice fed $10 \%$ fat and those fed $45 \%$ fat. (b) Caloric intake on the two diets. ${ }^{A} P<$ 0.05. (c) Effects of diets on serum leptin concentration. ${ }^{A} P<0.001$. of high-fat feeding in C57BL/6J mice. A defect at the level of leptin access is inferred from the fact that icv administration of leptin at least partially overcomes the diminished signaling observed after peripheral administration in these mice. These findings are consistent with the data of Van Heek et al. (11), who found that icv, but not ip leptin could diminish food intake and reduce body weight in a similar obesity model. Our data extends those physiologic findings to the level of signal transduction by demonstrating that leptininduced STAT3 activation is undetectable after ip leptin, but is present after icv leptin administration, after 15 weeks of high-fat diet. The molecular mechanism for the apparent defect in leptin access or transport remains unknown at present. Leptin transport into the brain may involve the ObRa isoform (short form) of the leptin receptor, which is highly expressed within the blood-brain barrier (13). In one study, expression of ObRa mRNA in cerebral microvessels of rats with DIO was increased (20). We therefore examined the expression of ObRa mRNA in cerebral microvessels of mice with 15-18 weeks of DIO, and observed that no change in the expression of ObRa mRNA was evident (Figure $4 b)$. In addition, we found no significant difference in expression of leptin receptor mRNA using primers designed to detect all known forms of ObR (ObRall, Figure 4b). Thus, the mechanism underlying what appears to be reduced leptin transport across the blood-brain barrier does not involve reduced expression of the mRNA encoding a putative leptin transporter within the blood-brain barrier. Further studies will be required to determine whether the protein expression or function of putative leptin transporters at the blood-brain barrier are impaired in DIO.

In addition to the defect in transport or availability of leptin, our data provide the first evidence that a second defect exists at the level of leptin signaling to activate STAT3 in DIO. Leptin activation of STAT3 requires the ObRb isoform (long form) of the leptin receptor, which associates with and activates Janus tyrosine kinase-2 (JAK2) in a ligand-dependent manner (21-24). One potential mediator of reduced STAT3 activation in the hypothalamus of DIO mice is SOCS3 , a suppressor of cytokine signaling, whose expression we have shown previously to be acutely induced by leptin in neurons expressing $\mathrm{ObRb}$ in the hypothalami of normal rodents $(14,25)$. Forced expression of SOCS-3 in mammalian cells antagonizes proximal leptin signaling, probably by binding to and antagonizing JAK activity (26). PIAS-3 (protein inhibitor of activated STAT) is a recently described antagonist of STAT3 DNA binding activity (27), whose mRNA expression has not previously been examined in the hypothalamus of normal mice. Using quantitative RT-PCR, we examined the expression of SOCS-3 and PIAS-3 mRNA in hypothalami of mice fed low-fat or high-fat diets for 18 weeks. No significant differences were found (Figure 4a). In addition, we found no significant difference in hypothalamic STAT3 or ObRb mRNA 
Figure 3

Leptin-induced STAT3 DNA-binding activity in hypothalami of mice on diets of $45 \%$ fat (HFD) and $10 \%$ fat (LFD). Mice were starved overnight and then received an ip or icv leptin injection. They were sacrificed 30 minutes later, and nuclear extractions were used for EMSA (see Methods). Each lane represents one hypothalamus. All experiments were performed twice with similar results. The arrows indicate the migration of the STAT-DNA complexes. LFD values are normalized to $100 \%$. (a and $\mathbf{b}$ ) Treatment with ip leptin $(100 \mu \mathrm{g})$ after 4 weeks on diets. (c and $\mathbf{d}$ ) Treatment with ip leptin $(100 \mu \mathrm{g})$ after 15 weeks on diets. ${ }^{A} P<$ 0.001. (e and f) Treatment with icv leptin $(0.5 \mu \mathrm{g})$ after 15 weeks on diets. ${ }^{A} P<0.03$.

expression between the two groups (Figure 4a). Thus, a molecular basis for the observed defect in leptin's ability to activate STAT3 signaling remains to be determined.

Although C57BL/6J mice fed high-fat diets for 15 weeks fail to activate detectable hypothalamic STAT3 signaling in response to peripheral leptin, it is worth noting that these DIO mice are less obese than $d b / d b$ mice that lack all receptor-dependent STAT signaling. Additionally, unlike $d b / d b$ mice, DIO mice are fertile. Thus, despite our demonstration of severely impaired hypothalamic STAT3 activation after ip leptin, some important leptin signals are clearly reaching target neurons within the central nervous system in these mice. How does this conclusion relate to our inability to detect STAT3 activation either basally or after ip lep- a

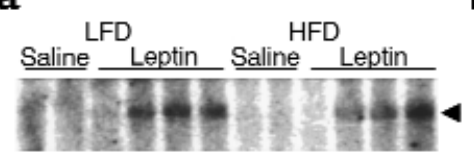

b

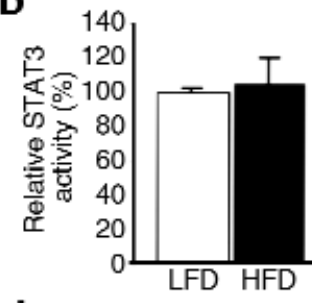

C

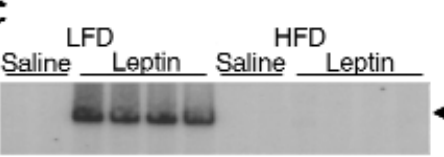

d

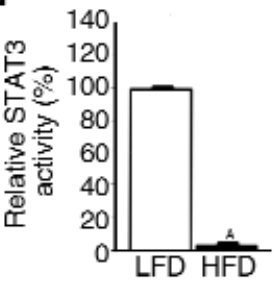

e

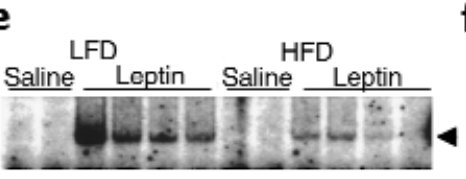

f

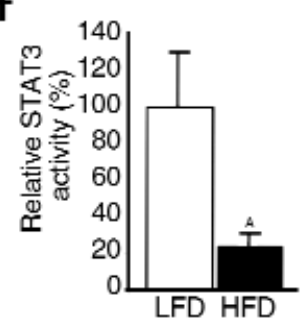

tin administration in mice with 15 weeks of DIO? The leptin receptor ObRb isoform activates the JAK/STAT pathway, but is capable of activating the MAP kinase (23) or PI-3 kinase pathway (28) in certain mammalian cell lines as well. It is therefore possible that STAT3 pathways are selectively inhibited in key neural groups, but important signals via MAP kinase or PI-3 kinase pathways are effectively transmitted. Alternatively, there may be key receptor signals transmitted through sites other than the hypothalamus that we did not sample. Finally, our assay may not be sensitive enough to pick up STAT3 activation in a limited, but functionally important subpopulation of leptin-responsive hypothalamic neurons. Understanding the mechanism by which substantial resistance to leptin's action on appetite and body weight coexists with persistent

\section{Figure 4}

(a) Hypothalamic mRNA expression of SOCS-3, PIAS-3, STAT3, and ObRb (long isoform of leptin receptor) after 18 weeks on a high-fat (white bars; $n=8$ ) or low-fat (black bars; $n=5$ ) diet. (b) Expression in brain microvessels of shortform leptin receptor (ObRa) mRNA and mRNA of all leptin receptor isoforms (ObRall) in mice on low-fat (white bars) or high-fat (black bars) diets. Gene expression was measured by quantitative RT-PCR as described in Methods. Values for low-fat diet are normalized to $100 \%$. Data are presented as mean \pm SEM. Microvessel experiments were performed three times with similar results. a

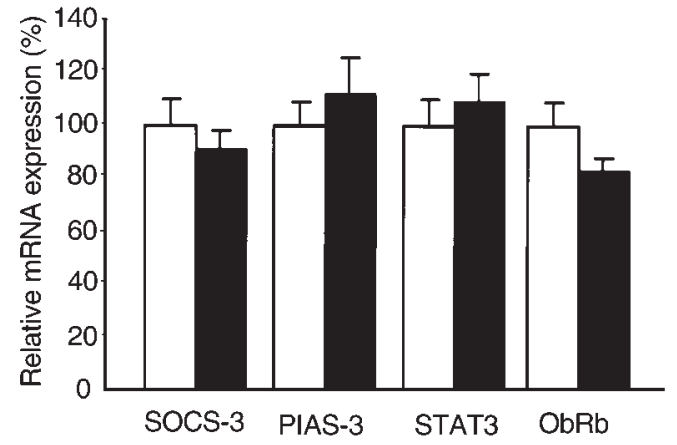

b

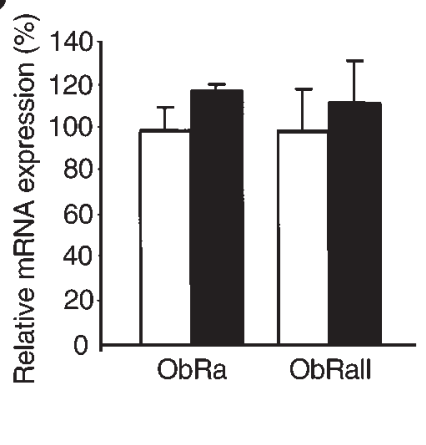


effects on neuroendocrine function should be an important goal of future research.

Leptin resistance is the hallmark of obesity induced by a high-fat diet in rodents, and occurs naturally in obese humans. If the factors limiting leptin action on appetite and body weight in human obesity are similar to those seen here in mice with DIO, then pharmaceutical development aimed at creating small-molecule leptin mimics with increased capacity to cross the blood-brain barrier might be effective in treating human obesity. On the other hand, a potential limitation of such an approach would be the factors that limit leptin signaling. It will be important in future studies to determine the precise molecular basis for this signaling defect.

\section{Acknowledgments}

This work was supported by grants from the National Institutes of Health (to J.S. Flier), Eli Lilly and Co. (to J.S. Flier), the Swiss National Scientific Research Foundation (to D.D. Pierroz), The Joslin Diabetes Center, DERC Pilot and Feasibility Study (to C. Bjørbæk), and the Deutsche Forschungsgemeinschaft (to K. El-Haschimi).

1. Zhang, Y., et al. 1994. Positional cloning of the mouse obese gene and its human homologue. Nature. 372:425-432.

2. Pelleymounter, M.A., et al. 1995. Effects of the obese gene product on body weight regulation in $o b / o b$ mice. Science. 269:540-543.

3. Halaas, J.L., et al. 1995. Weight reducing effects of the plasma protein encoded by the obese gene. Science. 269:543-546.

4. Ahima, R.S., et al. 1996. Role of leptin in the neuroendocrine response to fasting. Nature. 382:250-252.

5. Campfield, L.A., Smith, F.J., Guisez, Y., Devos, R., and Burn, P. 1995. Recombinant mouse OB protein: evidence for a peripheral signal linking adiposity and central neural networks. Science. 269:546-549.

6. Frederich, R.C., et al. 1995. Leptin levels reflect body lipid content in mice: evidence for diet-induced resistance to leptin action. Nat. Med. 1:1311-1314

7. Considine, R.V., et al. 1996. Serum immunoreactive-leptin concentrations in normal-weight and obese humans. N. Engl. J. Med. 334:324-325.

8. Caro, J.F., et al. 1996. Decreased cerebrospinal-fluid/serum leptin ratio in obesity: a possible mechanism for leptin resistance. Lancet. 348:159-161.

9. Schwartz, M.W., Peskind, E., Raskind, M., Boyko, E.J., and Porte, D., Jr.
1996. Cerebrospinal fluid leptin levels: relationship to plasma levels and to adiposity in humans. Nat. Med. 2:589-593.

10. Vaisse, C., et al. 1996. Leptin activation of Stat3 in the hypothalamus of wild-type and $o b / o b$ mice but not $d b / d b$ mice. Nat. Genet. 14:95-97.

11. Van Heek, M.V., et al. 1997. Diet-induced obese mice develop peripheral, but not central, resistance to leptin. J. Clin. Invest. 99:385-390.

12. Widdowson, P.S., Upton, R., Buckingham, R., and Williams, G. 1997. Inhibition of food response to intracerebroventricular injection of leptin is attenuated in rats with diet-induced obesity. Diabetes. 46:1782-1785.

13. Bjørbæk, C., et al. 1998. Expression of leptin receptor isoforms in rat brain microvessels. Endocrinology. 139:3485-3491.

14. Bjørbæk, C., Elmquist, J.K., Frantz, J.D., Shoelson, S.E., and Flier, J.S. 1998. Identification of SOCS-3 as a potential mediator of central leptin resistance. Mol. Cell. 1:619-625.

15. Schreiber, E., Matthias, P., Muller, M.M., and Schaffner, W. 1989. Rapid detection of octamer binding proteins with 'mini-extracts', prepared from a small number of cells. Nucleic Acids Res. 17:6419.

16. Levy, D.E., Kessler, D.S., Pine, R.I., and Darnell, J.E., Jr. 1989. Cytoplasmic activation of ISGF3, the positive regulator of interferon-alpha stimulated transcription, reconstituted in vitro. Genes Dev. 3:1362-1371.

17. Wagner, B.J., Hayes, T.E., Hoban, C.J., and Cochran, B.H. 1990. The SIF binding element confers sis/PDGF inducibility onto the c-fos promoter. EMBO J. 9:4477-4484.

18. Lee, G., et al. 1996. Abnormal splicing of the leptin receptor in diabetic mice. Nature. 379:632-635.

19. Chen, H., et al. 1996. Evidence that the diabetes gene is the leptin receptor-identification of a mutation in the leptin receptor gene in $\mathrm{db} / \mathrm{db}$ mice. Cell. 84:491-495.

20. Boado, R.J., Golden, P.L., Levin, N., and Padridge, W.M. 1998. Up-regulation of blood-brain barrier short-form leptin receptor gene products in rats fed a high fat diet. J. Neurochem. 71:1761-1764.

21. Ghilardi, N., et al. 1996. Defective STAT signaling by the leptin receptor in diabetic mice. Proc. Natl. Acad. Sci. USA. 93:6231-6235.

22. Baumann, H., et al. 1996. The full-length leptin receptor has signaling capacities of interleukin 6-type cytokine receptors. Proc. Natl. Acad. Sci. USA. 93:8374-8378.

23. Bjørbæk, C., Uotani, S., da Silva, B., and Flier, J.S. 1997. Divergent signaling capacities of the long and short isoform of the leptin receptor. $J$. Biol. Chem. 272:32686-32695.

24. Ghilardi, N., and Skoda, R.C. 1997. The leptin receptor activates janus kinase 2 and signals for proliferation in a factor-dependent cell line. Mol. Endocrinol. 11:393-399.

25. Elias, C.F., et al. 1999. Leptin differentially regulates NPY and POMC neurons projecting to the lateral hypothalamic area. Neuron. 23:775-786.

26. Bjørbæk, C., El-Haschimi, K., Frantz, J.D., and Flier, J.S. 1999. The role of SOCS-3 in leptin signaling and leptin resistance. J. Biol. Chem. 274:30059-30065.

27. Chung, C.D., et al. 1998. Specific inhibition of STAT3 signal transduction by PIAS3. Science. 278:1803-1805.

28. Harvey, J., et al. 2000. Essential role of phosphoinositide 3-kinase in leptin-induced K (ATP) channel activation in the rat CRI-G1 insulinoma cell line. J. Biol. Chem. 275:4660-4669. 